\title{
Periarthritis of the shoulder and diabetes mellitus
}

\author{
J. F. BRIDGMAN \\ St. James's Hospital, Balham, London S.W.12
}

Periarthritis of the shoulder (frozen shoulder) is a well-defined condition with its phases of severe pain, increasing stiffness, and the gradual recovery of full movement of the shoulder; these features usually occur over a number of months.

The aetiology of this condition, however, is not clearly understood. Amongst the factors suggested are trauma (Charnley, 1959), myocardial infarction (Minter, 1967), hemiplegia (Perzczyuski and Rardin, 1965), pulmonary tuberculosis (Johnson, 1959; Crossen and Hiltz, 1965), thyrotoxicosis (Oldham, 1959; Solal, 1965), cerebral tumour, and epilepsy (Thompson, 1961). In this paper, an association of periarthritis of the shoulder with diabetes mellitus is described. The incidence of this condition in diabetic patients is compared with that in nondiabetic medical patients seen during the same period of time.

\section{Methods and patients}

During a period of 12 months, 800 diabetics and 600 nondiabetic patients attending as out-patients at St. James's Hospital were examined for evidence of periarthritis of the shoulder. The Hospital Records of both groups of patients were also examined for information of a past history of periarthritis of the shoulder over a 10-year period. The 600 nondiabetics who acted as controls were fully ambulant and were of a similar age range. They attended regularly as out-patients and suffered from a wide variety of medical conditions not including diabetes. Those diabetics with coexisting illnesses known to be associated with periarthritis of the shoulder were excluded from the study. The duration and the treatment of the diabetes was recorded.

The diagnosis of periarthritis was made on the following criteria:

A history of shoulder pain sufficient to wake the patient at night and present for at least 3 months.

Progressive limitation of shoulder movement, particularly a reduction of at least half the normal range of external rotation.

Patients who had well-documented evidence of having passed through these stages and whose shoulder was undergoing recovery were also included.

The diabetics were assessed for evidence of a peripheral neuropathy, which was diagnosed by the presence of impaired vibration sense and absent ankle jerks. An autonomic neuropathy was looked for in those diabetics with affected shoulders and was based on the presence of a postural hypotension. The patient's blood pressure was taken in the lying position and then standing at 1 minute intervals up to 5 minutes. If there was a sustained drop in blood pressure of $10 \mathrm{~mm} . \mathrm{Hg}$ diastolic and $30 \mathrm{~mm}$. $\mathrm{Hg}$ systolic, the patient was regarded as having a significant degree of postural hypotension. The patient's other joints were examined for an active arthropathy and the presence of Dupuytren's contracture was also looked for. The affected shoulders were $x$ rayed, blood was taken for estimations of the serum uric acid, the erythrocyte sedimentation rate, and the latex-fixation test for rheumatoid factor. Results of the blood biochemistry were compared with a similar number of matched diabetics without shoulder involvement.

\section{Results}

$86(10 \cdot 8$ per cent.) diabetics and fourteen $(2 \cdot 3$ per cent.) non-diabetics were found to have periarthritis of the shoulder, a statistically significant difference between the two groups of patients $(P<0.005)$.

The details of the number of patients, site of the lesion, treatment of the diabetes, and the number of patients with neuropathies are recorded in Tables I and II. The various medical conditions with which the fourteen non-diabetics presented are outlined in Table III. The mean duration of the diabetic state was found to be 8.9 yrs (range 1 to 30 ), compared with a mean of 6.6 yrs (range $1 \mathrm{mth}$. to $36 \mathrm{yrs}$ ) for all the diabetics studied. Dupuytren's contractures were found in five of the affected diabetic group, fourteen of the non-diabetic group, and 22 of the total number of diabetics studied. The incidence of peripheral neuropathy was similar to that occurring in diabetics without shoulder involvement and included five with evidence of an autonomic neuropathy. The mean serum uric acid level and the erythrocyte sedimentation rate in the affected diabetic males was $4.6 \mathrm{mg}$. per cent. (range 2.7 to 9.0 ) and $14.8 \mathrm{~mm}$./1 st hr. (range 3 to 61). The corresponding results for the diabetic females was $3.5 \mathrm{mg}$. per cent. (range 1 to $5 \cdot 3$ ) and 
Table I Age at onset and site of lesion

\begin{tabular}{|c|c|c|c|c|c|c|c|c|c|}
\hline \multirow[t]{2}{*}{ Diagnosis } & \multirow{2}{*}{$\begin{array}{l}\text { No. of } \\
\text { patients } \\
\text { investigated }\end{array}$} & \multicolumn{3}{|c|}{$\begin{array}{l}\text { No. of patients with } \\
\text { periarthritis of the shoulder }\end{array}$} & \multicolumn{2}{|c|}{$\begin{array}{l}\text { Mean age at onset } \\
(y r s)\end{array}$} & \multicolumn{3}{|c|}{ Site of lesion } \\
\hline & & Total & Male & Female & Male & Female & Bilateral & Right & Left \\
\hline Diabetic & 800 & 86 & 32 & 54 & $\begin{array}{l}58 \cdot 25 \\
\text { (range } \\
44-78)\end{array}$ & $\begin{array}{l}59 \cdot 8 \\
\text { (range } \\
39-77)\end{array}$ & 36 & 26 & 24 \\
\hline Nondiabetic & 600 & 14 & 10 & 4 & $\begin{array}{l}57 \cdot 8 \\
\text { (range } \\
52-73 \text { ) }\end{array}$ & $\begin{array}{l}62 \cdot 75 \\
\text { (range } \\
54-72 \text { ) }\end{array}$ & 3 & 6 & 5 \\
\hline
\end{tabular}

Table II Particulars of diabetic patients

\begin{tabular}{|c|c|c|c|c|c|c|c|}
\hline \multirow[t]{2}{*}{ Series } & \multicolumn{3}{|c|}{ No. of patients } & \multirow[t]{2}{*}{ Insulin } & \multirow{2}{*}{$\begin{array}{l}\text { Oral } \\
\text { agents }\end{array}$} & \multirow[t]{2}{*}{ Diet } & \multirow{2}{*}{$\begin{array}{l}\text { Peripheral } \\
\text { neuropathy }\end{array}$} \\
\hline & Total & Male & Female & & & & \\
\hline $\begin{array}{l}\text { Diabetics with peri- } \\
\text { arthritis of the } \\
\text { shoulder }\end{array}$ & 86 & 32 & 54 & $\begin{array}{l}31 \\
(36 \%)\end{array}$ & $\begin{array}{l}37 \\
(43 \%)\end{array}$ & $\begin{array}{l}18 \\
(21 \%)\end{array}$ & $(31 \cdot 6 \%)$ \\
\hline $\begin{array}{l}\text { Total no. of diabetics } \\
\text { investigated }\end{array}$ & 800 & 363 & 437 & $\begin{array}{l}184 \\
(23 \%)\end{array}$ & $\begin{array}{l}400 \\
(50 \%)\end{array}$ & $\begin{array}{l}216 \\
(27 \%)\end{array}$ & $\begin{array}{l}280 \\
(35 \%)\end{array}$ \\
\hline
\end{tabular}

Table III Associated medical conditions in fourteen non-diabetics with periarthritis of the shoulder

\begin{tabular}{ll}
\hline Condition & No. of cases \\
\cline { 1 - 2 } Ischaemic heart disease & \\
Hypertension & 2 \\
Hypothyroidism & 1 \\
Pernicious anaemia & 1 \\
Cirrhosis & 1 \\
\hline
\end{tabular}

$20.8 \mathrm{~mm}$./1st hr. (range 4 to 44 ). These results were not significantly different from matched diabetic controls. There was only one diabetic with periarthritis of the shoulder who had a positive latexfixation test. $X$ rays of the affected shoulders showed no striking abnormalities, apart from two patients who had calcification of the articular cartilage suggestive of chrondrocalcinosis articularis.

\section{Discussion}

Laul (1967) investigated forty patients with the frozen shoulder syndrome, who were not previously known to be diabetic, and found the fasting blood sugar to be in the range of 135 to $150 \mathrm{mg}$. per cent. in 36 cases. Meulengracht and Schwartz (1952) analysed 78 medical cases who were admitted to hospital with periarthritis of the shoulder, and found that 21 (27 per cent.) had associated thyroid disorders and that three were also diabetics.

Although both shoulders were involved in 41.7 per cent. of the present series of patients, there was no relationship to a polyneuropathy which could have ? accounted for this symmetrical distribution. A reflex. sympathetic dystrophy has been suggested as a pos sible factor in the development of periarthritis of the shoulder (Steinbrocker, Neustadt, and Bosch, 1955; Thompson, 1961). An autonomic neuropathy would therefore give additional support to this theory. In fact, only five of the patients had evidence suggestive of autonomic dysfunction.

There is a significant correlation with the severity of the diabetes, as 36 per cent. of the affected patients were insulin-dependent compared with 23 per cent. of the original 800 diabetics investigated $(P<0.001)$. This fits in with the general pattern of insulin-dependent diabetics having a higher incidence of such complications as neuropathies, nephropathies, and the vascular effects of the disease.

Clinical features of polyarthropathy, such as rheumatoid arthritis, were not found in any of the patients and only one had a positive latex test. The erythrocyte sedimentation rate was not helpful. The serum uric acid levels were not statistically significant but helpful in excluding gout. Skinner and Cohen (1969) discovered diabetes in 72 per cent. of their series of patients with chrondrocalcinosis articularis. However, $x$ ray findings suggestive of this condition occurred in only two of the present series of patients, which precludes it as an aetiological factor.

A high incidence of Dupuytren's contracture in diabetics has often been quoted (Schneider, 1953; Ricci and Tovanella, 1963), and Meulengracht and Schwartz (1952) also found a high incidence in their series. Although the pathogenesis of this condition is 
not clearly understood, it was assumed that a similar process might occur in patients with periarthritis of the shoulder. However, Dupuytren's contracture was found in only five patients. Johnson (1959), in a series of patients with pulmonary tuberculosis, and Minter (1967), discussing patients with myocardial infarction, have suggested that immobilization was largely responsible for the development of periarthritis of the shoulder in these conditions. However, in this present series, the patients were fully ambulant and attended the diabetic clinic regularly.

In view of the association between the two conditions, it is obviously important to screen for diabetes in patients presenting with periarthritis of the shoulder, especially when there is bilateral shoulder involvement.

\section{Summary}

In a series of 800 unselected diabetics, $86(10.8$ per cent.) were found to have had a periarthritis of the shoulder (frozen shoulder). In 36 patients $(4.5$ per cent.), both shoulders were involved and there was a high incidence in insulin-dependent diabetics.

I am extremely grateful to Dr. A. Kahan for allowing me to study his patients and to Mr. V. Patel of the Orthopaedic Department for his help and encouragement. I am also indebted to Dr. F. Bruckner for his advice and helpful criticism of this paper and to Dr. A. C. Boyle whose idea stimulated me to carry out this project.

\section{References}

Charnley, J. (1959) Postgrad. med. J., 35, 384 (Periarthritis of the shoulder)

Crosson, E. W., AND Hiltz, J. E. (1965) Canad. med. Ass. J., 92, 1110 (Non-tuberculous disabilities in sanatorium patients)

Johnson, J. T. H. (1959) J. Bone Jt Surg., 41A, 877 (Frozen shoulder syndrome in patients with pulmonary tuberculosis)

LAUL, V. S. (1967) Indian Practnr, 20, 787 (Frozen shoulder syndrome)

MeUlengracht, E., AND SchwarTz, M. (1952) Acta med. scand., 143, 350 (The course and prognosis of periarthritis humeroscapularis with special regard to cases with general symptoms)

MINTER, W. T. (1967) J. med. Ass. Ga., 56, 45 (The shoulder-hand syndrome in coronary disease)

Oldham, B. E. (1959) N.Z. med. J., 58, 766 (Periarthrosis of the shoulder associated with thyrotoxicosis)

PeszCZynski, M., and Rardin, T. (1965) Bull. Pol. med. Sci. Hist., 8, 21 (The incidence of painful shoulder in hemiplegia)

Ricci, N., AND Tovanella, B. (1963) Minerva med. (parte sci.) 54, 3272 (Malattia di Dupuytren e diabete mellito)

SCHNEIDER, T. (1953) $S$. Afr. med. J., 27, 466 (Late manifestations of diabetes mellitus)

Skinner, M., AND CoHEN, A. S. (1969) Arch. intern. Med., 123, 6, 636 (Calcium pyrophosphate dihydrate crystal deposition disease)

Solal, M. C. (1965) Rhumatologie, 17, 329 (Périarthrite scapulo-humérale et algodystrophie)

Steinbrocker, O., Neustadt, D., AND Bosch, S. J. (1955) Med. Clin. N. Amer., 39, 563 (Painful shoulder syndromes)

Thompson, M. (1961) Proc. roy. Soc. Med., 54, 679 (Shoulder-hand syndrome) 